\title{
Uso e qualidade da água na microbacia hidrográfica do rio Parafuso (Moju, Pará, Brasil)
}

\author{
Use and water quality in the hydrographic microbasin of \\ Parafuso river (Moju, Para, Brazil) \\ Cláudia Miranda ${ }^{1}$, Leonilde Rosa ${ }^{2}$, Jorge Bonito ${ }^{3}$, Alcinês Júnior ${ }^{4}$, Nelson Veiga ${ }^{5}$, Francisco Oliveira ${ }^{6}$, Bruno Barros ${ }^{7}$ \\ ${ }^{1}$ Msc. Aluna do Programa de Pós-Graduação em Biologia Parasitária na Amazônia, Centro de Ciências Biológicas e da Saúde, Universidade do Estado do Pará, Brasil \\ - cllaumiranda@gmail.com \\ 2PhD. Professora Associada, Instituto de Ciências Agrárias, Universidade Federal Rural da Amazônia, Brasil - leonilders@yahoo.com.br \\ ${ }^{3}$ PhD. Professor Auxiliar com Agregação, Universidade de Évora, Portugal. CIDTFF, Universidade de Aveiro, Portugal - jbonito@uevora.pt \\ ${ }^{4}$ Msc. Professor, Escola Superior da Amazônia, Brasil - alcinesjunior@gmail.com \\ ${ }^{5}$ PhD. Professor Adjunto, Instituto Ciberespacial, Universidade Federal Rural da Amazônia, Brasil - nelsoncg2009@gmail.com \\ ${ }^{6}$ PhD. Professor Adjunto, Instituto de Ciências Agrárias, Universidade Federal Rural da Amazônia, Brasil - francisco.oliveira@ufra.edu.br \\ ${ }^{7}$ Msc. Aluno do Programa de Pós-Graduação em Virologia do Instituto Evandro Chagas, Brasil - brunocvb@yahoo.com.br
}

RESUMO: A ação antrópica ao longo dos anos, no entorno da microbacia do rio Parafuso, ocasionou impactos ambientais adversos sobre os recursos hídricos. Este estudo tem como objetivos avaliar a qualidade da água do rio Parafuso com base nos atributos físicos, químicos e microbiológicos e identificar os diferentes usos da água pela comunidade local, a fim de obter informação que possa subsidiar propostas para o manejo sustentável da microbacia. Para a avaliação da qualidade da água foram realizadas quatro campanhas, considerando a sazonalidade, com 19 pontos de amostragem. Foram realizadas entrevistas, observação direta e aplicados questionários para coletar os dados sobre os diferentes usos da água pela população local. Os resultados revelam a multifuncionalidade dos rios. Os índices do Ferro e E. coli, em alguns pontos amostrais, ultrapassam os limites exigidos pela legislação, o que denota o comprometimento da qualidade da água na referida microbacia para os diversos usos domésticos.

Palavras-chave: Amazónia, ação antrópica, microbacia, recursos hídricos, qualidade da água.

ABSTRACT: The anthropic action over the years on surroundings of Parafuso river microbasin caused adverse environmental impacts on water resources. This study aims to evaluate the water quality of Parafuso river and its tributary pass rote, based on physical, chemical and microbiological attributes, as well as identify the different uses of water by the local community, in order to obtain in formations to support proposals for the sustainable management of the microbasin. For the evaluation of water quality were conducted four campaigns, considering seasonality, with 19 sampling points. Were applied interviews, direct observation and questionnaires to collect data about the different uses of water, by the local population. The results showed the multifunctionality of the rivers. The contents of Iron and E. coli in some sample points surpass the limits required by legislation, which denotes the impairment of water quality in the microbasin for the various household uses.

Keywords: Amazon, anthropic action, microbasin, water resources, water quality. 


\section{INTRODUÇÃO}

A avaliação da água não pode restringir-se a um simples balanço entre oferta e potencial, mas deve abranger as suas interrelações geoambientais e socioculturais, bem como a conservação dos recursos naturais, a ocupação do território, tanto urbano como rural, para alcançar e garantir a qualidade do desenvolvimento sustentado (REBOUÇAS, 2006). Este pressuposto remete para o problema da degradação dos recursos hídricos e para a crescente escassez da água potável no planeta Terra, em quantidade e qualidade, para dar resposta às novas exigências da sociedade contemporânea. Em vista disso, a região Amazónica, no Brasil, pelas suas caraterísticas hidrográficas, assume um papel estratégico na discussão. Além das suas águas apresentarem problemas transfronteiriços, a qualidade está ameaçada pelas consequências do crescimento económico insustentável, tanto nas áreas urbanas como nas rurais.

Deste modo, faz-se necessário avaliar a qualidade da água nas microbacias situadas na região Amazónica, onde os rios apresentam diferentes usos pelas populações locais. Inserida neste contexto, encontra-se a microbacia do rio Parafuso em Moju, no Estado do Pará. ROSA (2002) elenca, na microbacia, inúmeras atividades antrópicas, dentre as quais se destacam a agropecuária e a atividade madeireira, que provocam a degradação e o empobrecimento das florestas primárias, incluindo as matas ciliares, gerando inúmeros impactos ambientais nas nascentes e na qualidade da água do rio Parafuso e do seu afluente, o rio Passarote, afetando diretamente a sustentabilidade dos recursos naturais da área.

Apesar das atividades antrópicas referidas ocasionarem alterações físico-químicas e biológicas nas águas do rio Parafuso e do seu afluente, que podem interferir na saúde das populações locais, esses rios são utilizados pelas mesmas populações com funções de lazer, para banhos diários de higiene e para abastecimento doméstico, entre outras.

Este trabalho teve como objetivo avaliar a qualidade da água na microbacia do rio Parafuso, com base nos atributos físicos, químicos e microbiológicos, bem como identificar os diferentes usos da água pela comunidade local, a fim de obter informação que possa subsidiar propostas para a conservação e gestão sustentável da referida microbacia e contribuir para a criação de políticas públicas, que visem melhorar a qualidade de vida dos moradores locais.

\section{MATERIAL E MÉTODOS}

\section{1. Área de estudo}

A pesquisa foi realizada na microbacia hidrográfica do rio Parafuso no assentamento Olho D'Água I ( $2^{\circ} 19^{\prime} 51^{\prime \prime}$ S e $\left.46^{\prime} 06^{\prime \prime} \mathrm{W}\right)$, no município de Mojú, Mesorregião do nordeste paraense, Estado do Pará (Brasil). Esta microbacia possui aproximadamente 9 $\mathrm{km}^{2}$ (Figura 1).

O rio Parafuso é tributário do rio Ubá, um dos principais afluentes do rio Mojú. A microbacia faz parte de um conjunto hidrográfico que compõe a região Costa Atlântica Nordeste, Sub-região do Guamá-Mojú, uma área estratégica para implantação do modelo de gestão das águas na Amazónia, por ser considerada a região mais densamente povoada do Estado do Pará.

Na região, de acordo com a classificação de Köppen, o clima é do tipo Ami, com temperatura média anual entre $25-27^{\circ} \mathrm{C}$ e precipitações anuais entre 2000$3000 \mathrm{~mm}$, com distribuição irregular, ocorrendo pequeno período seco (SANTOS et al., 1985). Segundo os autores, na área de abrangência do estudo predomina o Latossolo Amarelo (LA), com diferentes texturas, ocorrendo também Podzólico Vermelho-Amarelo (PV), Glei Pouco Húmico (HGP) e Plintossolos. A área de abrangência da microbacia do rio Parafuso apresenta-se parcialmente recoberta com fragmentos de floresta primária com diferentes níveis de alteração antrópica, representados principalmente pela mata ciliar (SOUZA, 2007).

As médias mensais de precipitação pluviométrica no período de estudo, registadas pela estação meteorológica da Biopalma da Amazônia, S.A., evidenciam o processo de sazonalidade, com dois períodos distintos: o período de estiagem, que compreende os meses de julho a novembro; e o período chuvoso, que se estende do mês de dezembro ao mês de maio (Tabela 1). Observase, na tabela 1 , que no período compreendido entre junho a dezembro do ano de 2010, o mês de novembro apresentou menor índice pluviométrico (36 mm), enquanto no ano de 2011 no mês de abril foi registado o maior índice pluviométrico (518 $\mathrm{mm})$.

\subsection{Avaliação do uso da água pelos moradores locais}

Para estudar os diferentes usos da água do rio Parafuso e do seu afluente, pela população local, foram utilizadas ferramentas do Diagnóstico Rural Rápido Participativo (VERDEJO, 2006), como entrevistas semiestruturadas com 80 moradores 


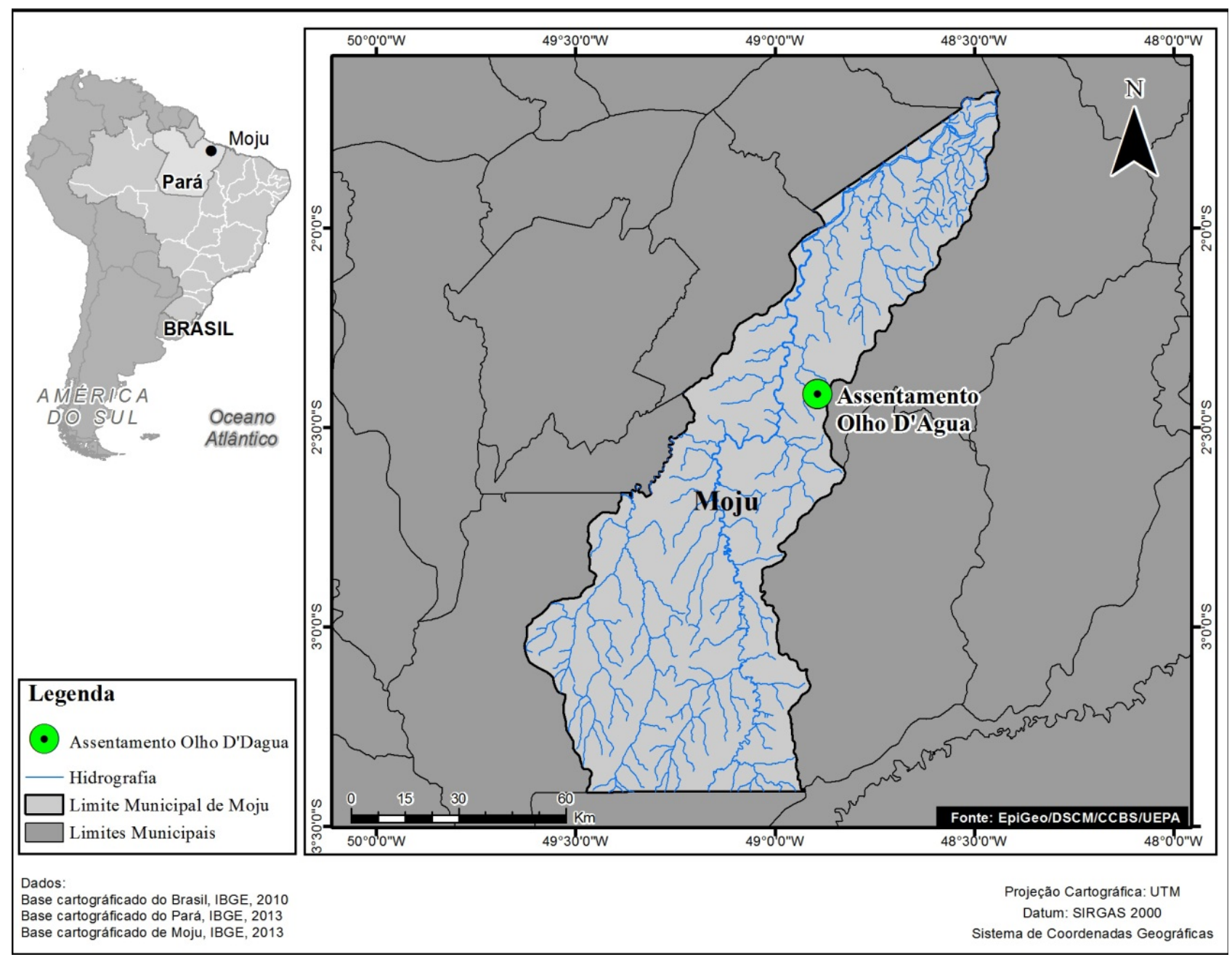

Figura 1. Localização da microbacia hidrográfica do rio Parafuso em Moju, PA. Fonte: EpiGeo/DSCM/CCBS/UEPA.

Tabela 1. Índice pluviométrico mensal (mm) na microbacia do rio Parafuso, durante o período de junho de 2010 a junho de 2011.

\begin{tabular}{|c|c|c|c|c|c|c|c|c|c|c|c|c|c|}
\hline Anos & jan & fev & mar & abr & mai & jun & jul & ago & set & out & nov & dez & Total \\
\hline 2010 & - & - & - & - & - & 198 & 78 & 74 & 67 & 40 & 36 & 392 & 885 \\
\hline 2011 & 235 & 241 & 278 & 518 & 400 & 220 & - & - & - & - & - & - & 1892 \\
\hline
\end{tabular}

Fonte: Dados coletados na estação meteorológica da Empresa Biopalma da Amazônia, S.A. Unidades: mm.

locais, observação direta com registro fotográfico e questionários aplicados aleatoriamente a 186 moradores e, ainda, o mapeamento participativo. Foram realizadas, também, reuniões informais, que permitiram obter informação relevante referente ao cotidiano dos moradores da área em estudo.

A participação de diferentes atores sociais (estudantes, professores, agricultores, funcionários de empresas privadas, moradores em geral) e "informantes-chaves" (professor, agente de saúde, enfermeiro, produtor, lideranças sindicais, diretores de cooperativas e moradores antigos) favoreceu a triangulação e aumentou a segurança dos dados coletadas.

\subsection{Avaliação da qualidade físico-química e microbiológica da água}

Para avaliar a qualidade da água e compreender as interferências provocadas pelas ações antropogénicas, foram realizadas coletas de água sazonalmente nos dois rios, sendo duas amostragens durante o período de estiagem e duas amostragens no período chuvoso. Para isso, foram instalados 19 pontos equidistantes de coleta para amostragem, sendo 10 pontos instalados no rio Parafuso e 9 no rio Passarote (Figura 2). A instalação dos pontos de coleta levou em conta as diferentes fontes de poluição e os sistemas de uso da terra no entorno da microbacia de estudo. 


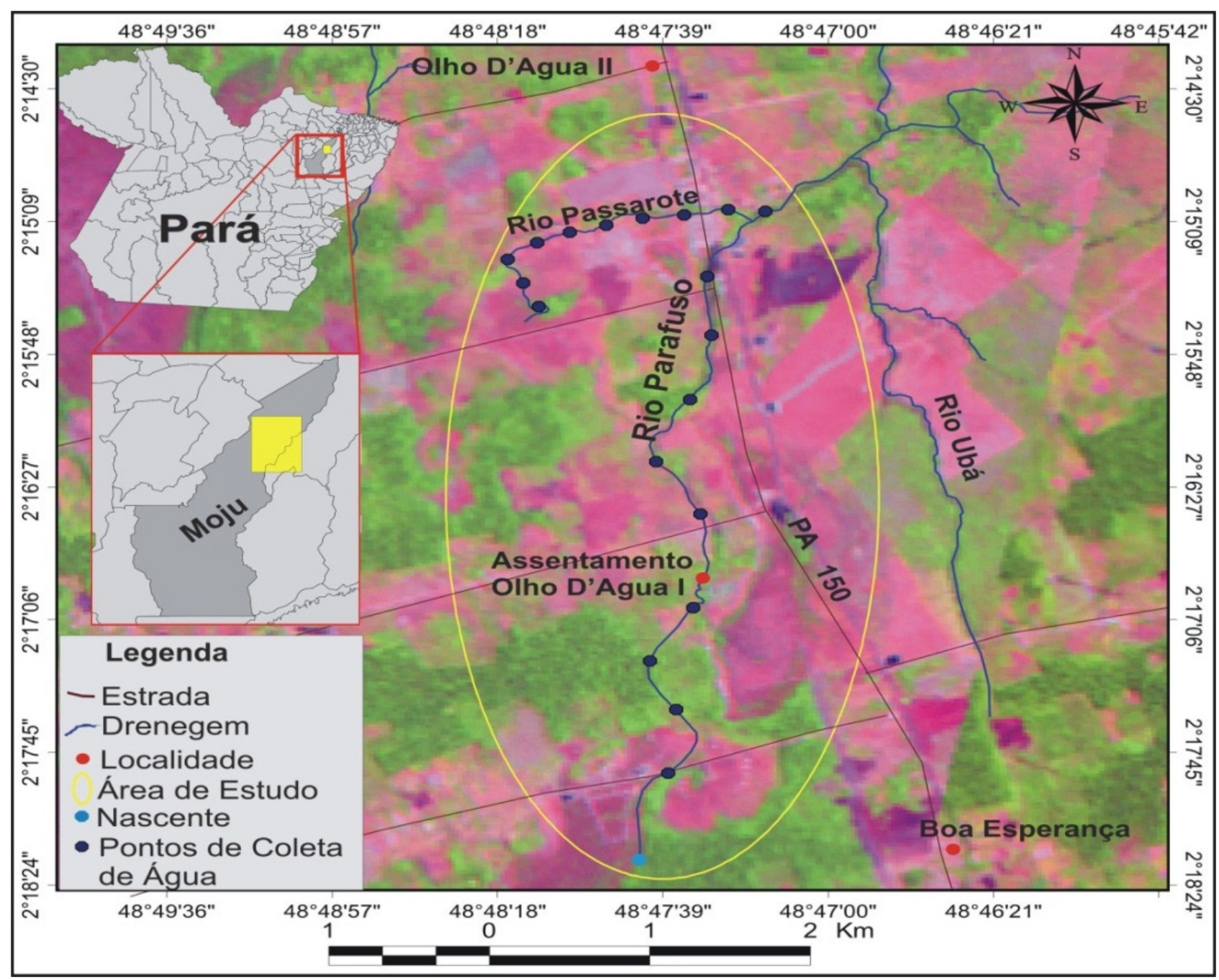

Figura 2. Localização dos 19 pontos para a coleta de água na microbacia hidrográfica do rio Parafuso. Fonte: EpiGeo/DSCM/CCBS/UEPA.

A caraterização e o ordenamento da microbacia de estudo, bem como a localização e instalação dos pontos de coleta, foram realizados com auxílio de técnicas de geoprocessamento, cartas cartográficas, imagens digitais e georreferenciamento. As coordenadas foram obtidas com o auxílio de um GPS (modelo Garmin 12 XL - Programa Track Macker).

Na recolha de amostras de água foram utilizadas bolsas esterilizadas tipo Nasco. Para obtenção da carência bioquímica de oxigénio (CBO) foram usadas garrafas de vidro devidamente esterilizadas. Os recipientes foram etiquetados, identificando o número do ponto, a hora e data de coleta. As amostras foram acondicionadas numa caixa térmica com gelo e, de seguida, transportadas para Belém (PA, Brasil).

Duranteacoletadasamostras deágua,foimensurada a temperatura da água, utilizando termómetro de filamento de mercúrio (marca Incoterm). A análise físico-química e microbiológica da água foi realizada no Laboratório Central do Estado do Pará - LACEN.
Foram analisados os seguintes parâmetros: CBO, coliformes totais, Escherichia coli, ferro, nitrogénio amoniacal, oxigénio dissolvido, $\mathrm{pH}$, sólidos totais, temperatura e turbidez.

Todos os procedimentos de coleta e acondicionamento seguiram as recomendações metodológicas descritas no Guia Nacional de Coleta e Preservação de Amostras (CETESB, 2011). Os parâmetros de qualidade de água analisados foram comparados com os limites preconizados pela Resolução CONAMA n. ${ }^{\circ}$ 357/2005, de 17 de março de 2005 (BRASIL, 2005), que define os limites e critérios para o enquadramento de corpos de água em classe 2. A Tabela 2 apresenta, resumidamente, a metodologia analítica empregada para a análise dos parâmetros físico-químicos e microbiológicos.

\subsection{Análise dos dados}

Para auxiliar a interpretação e discussão dos resultados sobre o uso da água na microbacia do 
rio Parafuso, foi elaborada uma tabela contendo os principais usos dados pelos moradores locais. Os dados coletados referentes aos parâmetros físicoquímicos e microbiológicos foram analisados com recurso testes de estatística descritiva e, de seguida, comparados com os limites preconizados pela Resolução CONAMA n. ${ }^{\circ}$ 357/2005.

\section{RESULTADOS E DISCUSSÃO}

\subsection{Usos das águas dos rios}

Os resultados obtidos mostram a multifuncionalidade dada às águas, tanto do rio Parafuso quanto do seu afluente Passarote e, ainda, que estes rios estão inseridos no cotidiano dos moradores locais. Cerca de $84,4 \%$ dos residentes utiliza os rios de várias formas e somente $15,6 \%$ não os utiliza para nenhum fim ou não sabem informar (Tabela 3).
Verifica-se na Tabela 3 que $64 \%$ dos moradores utiliza o rio para tomar banho, lazer e para atividades domésticas (lavar roupa e louça). Quase 9\% dos moradores locais pratica a pesca artesanal no rio Parafuso, denotando que o mesmo ainda exerce um papel importante no fornecimento de proteína animal e, por conseguinte, na segurança alimentar destes moradores. Vale salientar que todas as formas de uso do rio são consideradas de contacto primário, ou seja, o usuário tem contacto direto com a água (Figura 3 ).

Como identificado na Tabela 3 e Figura 3, é notória a importância e utilização dos rios, por ser considerado um espaço que abriga as diversas atividades humanas. Porém, este facto não é suficiente para que os moradores locais conservem os recursos hídricos, pois as ações antrópicas praticadas por eles não são sustentáveis. O desmatamento da mata ciliar para o estabelecimento da agrovila, das atividades agrícolas e pecuária, por exemplo,

Tabela 2. Análises físicas, químicas e microbiológicas e suas respectivas metodologias.

\begin{tabular}{|l|l|c|}
\hline Variável & Metodologia & Limite de deteção \\
\hline Temperatura & Termometria & $0,1^{\circ} \mathrm{C}$ \\
\hline $\mathrm{pH}$ & Potenciometria & 0,01 \\
\hline Turbidez & Turbidometria & $1 \mathrm{NTU}$ \\
\hline Ferro & Colorimétrico & $0,1 \mathrm{mg} / \mathrm{L}$ \\
\hline Sólidos totais & Condutivimetria & $1,0 \mathrm{mg} / \mathrm{L}$ \\
\hline Nitrogénio amoniacal & Colorimétrico & $0,10 \mathrm{mg} / \mathrm{L}$ \\
\hline CBO & Medição manométrica & $0,1 \mathrm{mg} / \mathrm{L}$ \\
\hline Oxigénio dissolvido & Colorimétrico & $0,1 \mathrm{mg} / \mathrm{L}$ \\
\hline Coliforme total & Enzima substrato quantitativo & $1 \mathrm{NMP}$ \\
\hline Escherichia coli & Enzima substrato quantitativo & $1 \mathrm{NMP}$ \\
\hline
\end{tabular}

Tabela 3. Principais usos da água na microbacia do rio Parafuso.

\begin{tabular}{|l|c|c|}
\hline Utilização do rio & Quantidade de moradores & Percentagem (\%) \\
\hline Lazer & 48 & 25,8 \\
\hline Atividade doméstica & 40 & 21,5 \\
\hline Tomar banho & 31 & 16,7 \\
\hline Não utilizam & 18 & 9,7 \\
\hline Utilização para pesca artesanal & 17 & 9,1 \\
\hline Não sabem informar & 11 & 5,9 \\
\hline Colocar a mandioca de molho & 8 & 4,3 \\
\hline Uso da água para dar de beber aos animais & 8 & 4,3 \\
\hline Abastecimento de água & 5 & 2,7 \\
\hline Total (no de amostras) & 186 & $\mathbf{1 0 0}$ \\
\hline Fonte: Pesquisa de campo & & \\
\hline
\end{tabular}



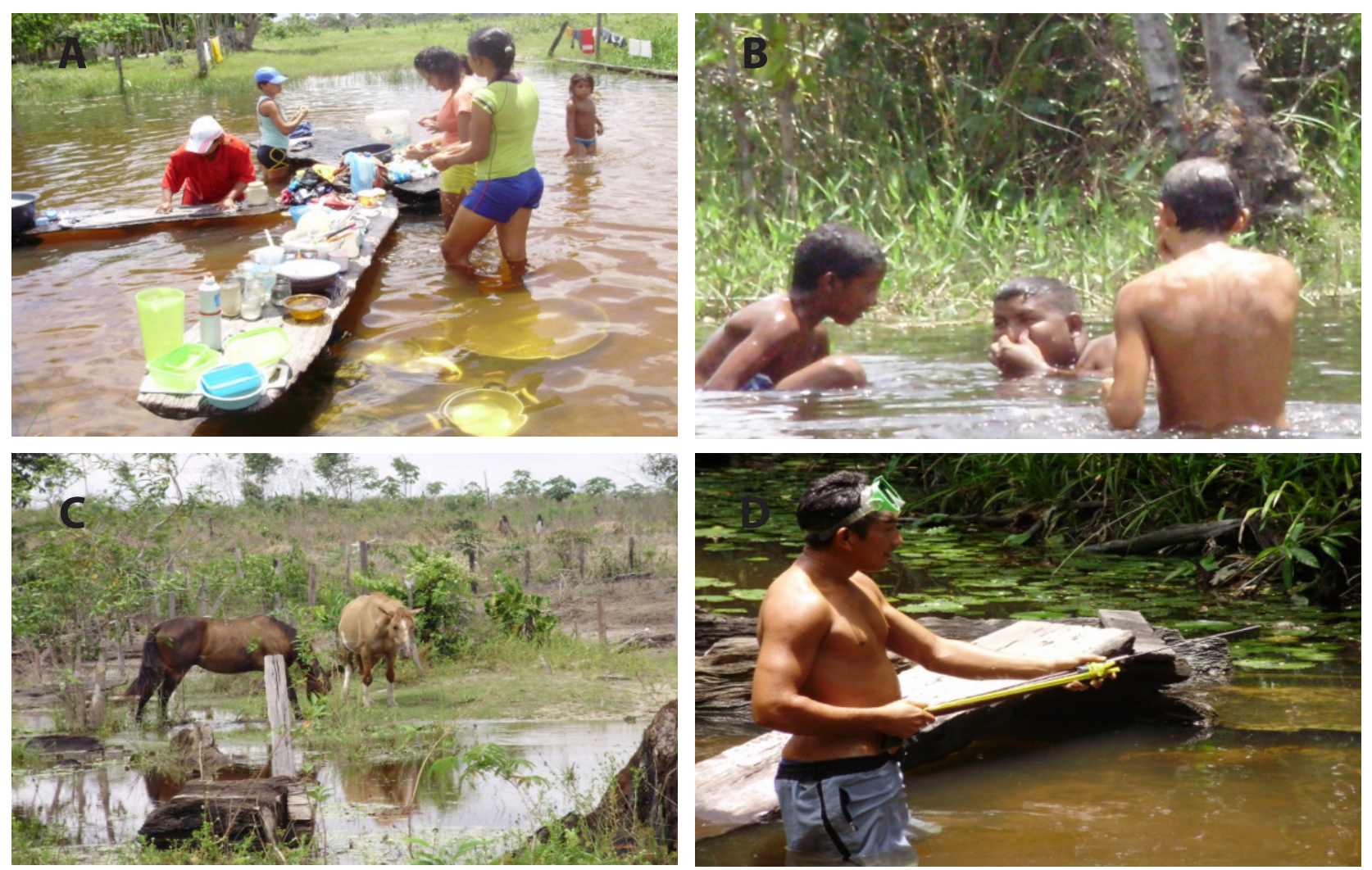

Figura 3. Multifuncionalidade do rio Parafuso. Usos do rio para lavar roupa e louça (A); lazer (B); criação de animais (C); para pesca (D).

Fonte: autores.

tem uma relação intrínseca entre o uso do solo e as águas dos rios da microbacia em estudo. Neste sentido, registos na literatura mostram que a diminuição da qualidade da água está diretamente relacionada com a conversão de áreas florestadas, principalmente para o uso agrícola ou urbano (AGUIAR et al., 2014; PEREIRA et al., 2016).

\subsection{Análise físico-química e microbiológica da água}

Os valores médios dos parâmetros físico-químicos e microbiológicos da água coletada na microbacia do rio Parafuso encontram-se na Tabela 4. De maneira geral, observa-se que ocorrem pequenas diferenças entre os valores médios da temperatura da água nos períodos de estiagem e chuvoso. O maior valor de temperatura éconstatado duranteo período chuvoso e menor no período seco. O fato pode ser atribuído ao horário diferenciado da realização da coleta, que ocorreu em virtude das grandes precipitações do período chuvoso no horário matutino. Neste sentido, estudos realizados por PINHEIRO (1987) no estuário Guajarino, no município de Belém, demonstram que a temperatura da água e as suas oscilações são influenciadas pelas variações horárias, sendo que amplitude da variação diária é maior do que a amplitude sazonal.
Para ESTEVES (1998), nos trópicos as variações da intensidade luminosa e da temperatura são reduzidas entre diferentes estações do ano, mas com grandes variações no decorrer de 24 horas. Análises na microbacia do rio Arari, no Estado do Pará, realizadas por ALVES et al. (2012), revelam que ocorrem pequenas variações temporais no parâmetro temperatura. As maiores temperaturas foram registadas durante o período menos chuvoso, enquanto a menor foi encontrada durante o período de chuvoso. Cabe destacar que a temperatura é uma variável fundamental para a manutenção da vida aquática. Este fator ambiental controla todos os processos químicos ocorridos nos cursos de água, interferindo diretamente na capacidade de autodepuração, fenómeno natural em que o curso hídrico retorna às suas caraterísticas iniciais depois de cessado o lançamento de efluentes (MOTA, 1997).

Os valores médios do $\mathrm{pH}$ nos períodos chuvoso e de estiagem são muito próximos, ocorrendo em torno de 5,7, mostrando que a água do rio Parafuso apresenta ligeira acidez. Este fato pode estar associado à quantidade de compostos ácidos presentes na água, resultantes da decomposição de material orgânico do ambiente e da contribuição da 
área da bacia hidrográfica (SIOLI, 1957; PAIVA et al., 2006; ALVES et al., 2012; SIQUEIRA et al., 2012).

Os valores máximos e mínimos encontrados para o $\mathrm{pH}$ nos dois períodos de avaliação no rio Parafuso não revelam variações muito expressivas. De um modo geral, os resultados estão abaixo ou no limite inferior dos valores padrão 6 a 9 para a qualidade de massas de água, recomendados pela Resolução CONAMA n. ${ }^{\circ}$ 357/2005.

Os valores médios do $\mathrm{pH}$ da água recolhida no rio Parafuso e no seu afluente são ligeiramente maiores que os valores obtidos por AGUIAR et al. (2014) no município de Santarém-PA. Os autores observaram médias ligeiramente ácidas de $\mathrm{pH}$ e variações não significativas do $\mathrm{pH}$ entre os períodos de amostragem. Os valores de $\mathrm{pH}$ encontrados pelos autores apresentam-se abaixo da faixa estabelecida pela legislação, com medianas de 4,9-5,6, durante a estação seca, enquanto, para a estação chuvosa, os valores oscilaram entre 4,9-5,4. Do mesmo modo, SILVA (2006), nos seus trabalhos sobre a avaliação da qualidade da água da Baía do Guajará e do Rio Guamá-PA, também não observou variações significativas do $\mathrm{pH}$ entre os períodos de amostragem, determinando valores entre 5,196,39.

Os valores médios de turbidez da água do rio Parafuso na época chuvosa e na de estiagem apresentam amplitude relativamente elevada, respetivamente, de 14,06-25,95 UNT. O aumento da turbidez no período de estiagem decorre, provavelmente, da diminuição do caudal de água do rio, adicionado à presença de grande quantidade de material em suspensão presente nesse período (argilas, colóides, matéria orgânica, entre outros). Considerando os resultados apresentados na Tabela 1, de forma geral os valores de turbidez nos períodos de estudo apresentam-se dentro da faixa estabelecida pela legislação que preconiza para as massas de água de classe 2 até 100 NTU.

Os resultados obtidos indicam problemas pontuais ao longo do rio. Os pontos 1, 2 e 10 amostrados na microbacia hidrográfica do rio Parafuso apresentam os maiores valores de turbidez no período de estiagem (109 NTU, 107 NTU e 151 NTU, respectivamente). Estes valores ultrapassaram o estabelecido pela Resolução do CONAMA n. ${ }^{\circ}$ 357/2005.

Foi observado, in loco, que os pontos 1 e 2 se apresentam comprometidos pela deposição de material oriundo da caixa de empréstimo, de onde foram retiradas terras para a construção de estradas. Para além deste aspeto, nesses pontos foi construída uma barragem para criação de animais, facto que contribui para a deposição de sedimentos. No ponto 10 acredita-se que a turbidez tenha sido gerada, principalmente, pela retirada de areia do leito do rio para construções de novas casas na área da vila Olho d'Água.

SANTOS et al. (2013), no estudo realizado no lago Água Preta, um dos reservatórios de água superficial que abastece a Região Metropolitana de Belém,

Tabela 4. Valores médios, medianas, máximos e mínimos de variáveis físico-químicas da água coletada na microbacia hidrográfica do rio Parafuso Moju, PA.

\begin{tabular}{|c|c|c|c|c|c|c|c|c|c|c|}
\hline $\begin{array}{l}\text { Parâmetros } \\
\text { Medidas }\end{array}$ & $T$ & $\mathrm{pH}$ & UNT & ST & $\mathrm{Fe}$ & $\mathbf{N}$ & OD & СВО & CT & E. coli \\
\hline \multicolumn{11}{|l|}{ Chuvoso } \\
\hline Média & 29,00 & 5,75 & 14,06 & 16,98 & 0,30 & 0,35 & 8,88 & 0,32 & 5829,75 & 290,86 \\
\hline Máximo & 29,50 & 6,94 & 35,88 & 96,40 & 0,80 & 0,90 & 12,50 & 1,30 & $24.196,00$ & 2755,00 \\
\hline Mínimo & 28,00 & 4,60 & 3,64 & 0,30 & 0,10 & 0,10 & 5,00 & 0,00 & 480,00 & 10,0 \\
\hline Mediana & 29,10 & 5.70 & 8,20 & 13,60 & 0,30 & 0,35 & 9,15 & 0,20 & 5202,50 & 146,00 \\
\hline \multicolumn{11}{|l|}{ Estiagem } \\
\hline Média & 27,72 & 5,71 & 25,95 & 18,46 & 1,34 & 0,36 & 8,46 & 0,53 & 6919,78 & 264,39 \\
\hline Máximo & 29,20 & 6,44 & 151,0 & 41,90 & 4,00 & 0,80 & 18,56 & 1,40 & $15.329,00$ & 860,00 \\
\hline Mínimo & 26,00 & 5,07 & 4,05 & 10,00 & 0,30 & 0,00 & 6,00 & 0,20 & 2046,00 & 10,00 \\
\hline Mediana & 27,75 & 5,62 & 12,84 & 17,94 & 0,80 & 0,30 & 6,60 & 0,40 & 5196,00 & 215,00 \\
\hline
\end{tabular}

Obs: T - Temperatura $\left({ }^{\circ} \mathrm{C}\right) ; \mathrm{UNT}$ - Unidades Nefelométricas de Turbidez; ST - Sólidos totais dissolvidos (mg/L); Ferro (mg/L); $\mathrm{N}$ - Nitrogénio amoniacal (mg/L); OD - Oxigénio dissolvido (mg/L); CBO - Carência bioquímica de oxigénio ( $\mathrm{mg} / \mathrm{L}) ; \mathrm{CT}$ Coliformes totais (NMP/100 mL); Escherichia coli (NMP/100 mL). 
comparam as variações mensais de turbidez com as médias mensais de precipitação pluviométrica do período estudado. Os autores verificam que em meses de maior precipitação são registados menores valores de turbidez, enquanto em meses com pouca chuva existe elevação nos valores de turbidez nos lagos, demonstrando a diluição das águas do lago pelas águas das chuvas.

Nos resultados encontrados por AMORIM et al. (2010), no rio Parauapebas-PA, os valores da turbidez da água alteram-se de acordo com as variações sazonais, indicando maior turbidez no período chuvoso (87,3 NUT) e menor no período $\operatorname{seco}(18,2$ NUT).

$\mathrm{Na}$ Tabela 4 percebe-se que o valor médio de concentração de sólidos totais (ST) é maior na época de estiagem (18 mg/L), explicando-se por todos os contaminantes da água, com exceção dos gases dissolvidos, contribuirem para a carga de sólidos presentes. Ainda assim, a quantidade de minerais contidos na água pode diminuir por diluição (água da chuva) ou aumentar pela adição de detritos industriais.

RIBEIRO (2004) também encontrou altos valores de ST no lgarapé do Paracuri-PA, na época de estiagem (48,3 mg/L), o mesmo não acontecendo no rio Combu (25,5 mg/L). ALVES et al. (2012) encontraram as maiores concentrações de ST no período menos chuvoso $(221,0 \mathrm{mg} / \mathrm{L})$ na bacia hidrográfica do rio Arari, localizada na porção leste da ilha do MarajóPA. Os autores observaram que na época chuvosa houve diminuição das concentrações.

Relativamente ao elemento ferro (Tabela 4), verificase um aumento expressivo da concentração no período de estiagem $(1,34 \mathrm{mg} / \mathrm{L})$ comparativamente ao período chuvoso $(0,30 \mathrm{mg} / \mathrm{L})$. A concentração deste elemento, na maioria dos pontos de análise, é superior ao valor $0,3 \mathrm{mg} / \mathrm{L}$ estabelecido pela Resolução CONAMA n. ${ }^{\circ}$ 357/2005. O aumento da concentração desse elemento pode estar associado a diversos fatores observados no campo, entre eles, o processo avançado de erosão e assoreamento em que se encontra a microbacia e as atividades de extração de areia no leito do rio para a construção de novas moradias nas margens do rio Passarote e do seu afluente.

SIQUEIRA et al. (2012), no seu estudo no rio Parauapebas-PA, também observaram que o elemento $\mathrm{Fe}$, em pontos específicos, não se encontrava no padrão estabelecido pela referida legislação. Segundo os autores, a maior concentração de ferro foi encontrada na área urbana, com médias de 0,52 mg/L.

As concentrações de nitrogénio amoniacal, nos diferentes períodos do ano, apresentam valores médios próximos, tanto no período chuvoso $(0,35$ $\mathrm{mg} / \mathrm{L})$ quanto no de estiagem $(0,36 \mathrm{mg} / \mathrm{L})$. As concentrações médias encontram-se dentro dos padrões estabelecidos pela Resolução CONAMA n. 357/2005 (o valor máximo permitido é de 3,7 mg/L para $\mathrm{pH} \leq 7,5)$. O nitrogénio amoniacal, em geral, está relacionado com a existência de efluentes e águas poluídas (MOTA, 1995). Com o passar do tempo, o nitrogénio orgânico é convertido em nitrogénio amoniacal e, posteriormente, se existem condições aeróbias, a oxidação da amónia ocorre, transformando-se em nitrito e nitrato.

O parâmetro químico oxigénio dissolvido (OD) também é fundamental para o diagnóstico da qualidade do meio hídrico. No rio Parafuso, a média geral obtida de OD foi de $8,46 \mathrm{mg} / \mathrm{L}$ no período de estiagem e de $8,88 \mathrm{mg} / \mathrm{L}$ no período chuvoso, enquandrando-se na Resolução CONAMA n. ${ }^{\circ}$ 357/2005 (para rios de classe $2, O D \geq 5 \mathrm{mg} / \mathrm{L}$ ). AMORIM et al. (2010), no rio Parauapebas-PA, encontraram valores de $O D$ que variam entre 5,3-10,2 mg/L. Todos os resultados encontrados ficam acima do valor mínimo estabelecido pelo enquadramento das massas de água superficiais, indicando, assim, uma excelente qualidade da água segundo este indicador.

No município de Santarém-PA, a maioria das microbacias estudadas por AGUIAR et al. (2014) apresentam teores de OD normais para os dois períodos sazonais, com maiores valores registados durante a estação das chuvas $(5,1-9,1 \mathrm{mg} / \mathrm{L}) \mathrm{em}$ relação ao período seco (2,1-8,6 mg/L). Todos os pontos da área de referência revelam, no período seco, valores abaixo do limite mínimo estabelecido, mas que se restabelecem durante a estação chuvosa.

A CBO demonstra, indiretamente, a quantidade de matéria orgânica presente na massa de água. $A$ análise das amostras aponta que a $\mathrm{CBO}$, nos dois períodos em estudo (período chuvoso - 0,32 $\mathrm{mg} / \mathrm{L}$; período de estiagem $0,53 \mathrm{mg} / \mathrm{L}$ ), está em conformidade com o limite estabelecido de $5 \mathrm{mg} / \mathrm{L}$ pela Resolução CONAMA n. ${ }^{\circ}$ 357/2005.

AMORIM et al. (2010), analisando o rio Parauapebas$P A$, encontraram valores de $C B O$ que variam de entre $0,5-2,0 \mathrm{mg} / \mathrm{L}$ no período de estudo, enquanto AGUIAR et al. (2014), ao avaliarem a qualidade da água no município de Santarém-PA, encontraram menores concentrações de CBO (mediana de 0,2 $\mathrm{mg} / \mathrm{L}$ ) durante a estação chuvosa. Segundo os autores, não foi observado comprometimento dos níveis de OD na água pela quantidade de matéria orgânica no período estudado.

Os coliformes totais (CT) são bons indicadores da qualidade das águas, sobretudo em relação à poluição por efluentes domésticos (SHIBATA 
et al., 2004; APHA, 2005; ORTEGA et al., 2009). Assim, a determinação da concentração dos CT assume importância como parâmetro indicador da ocorrência de microrganismos patogénicos, responsáveis pela transmissão de doenças de veiculação hídrica, tais como a cólera e as febres tifóide e paratifóide.

Percebe-se na microbacia do rio Parafuso que o valor médio de CT é maior no período de estiagem (6920 NMP/100 mL). Os valores médios mais altos de CT são encontrados no rio Passarote, afluente do rio Ubá, que banha a Vila Olho d'água. $A$ análise da concentração de $E$. coli dá conta que o valor médio é maior no período chuvoso (291 NMP/100 mL) comparativamente ao período de estiagem (264 $\mathrm{NMP} / 100 \mathrm{~mL}$ ), em que as planícies de inundação e os quintais das propriedades, onde estão construídos sanitários com fossas séticas, são atingidos pelas águas.

ZUFFO et al. (2013), na caracterização da qualidade de águas superficiais em cinco das principais bacias hidrográficas do Estado de Rondônia, atestam a presença de CT em todas as bacias hidrográficas estudadas. SOUZA et al. (2015), na análise microbiológica do alto rio Pedreira-AP, identificam a presença de coliformes fecais apenas no período chuvoso.

A presença de $\mathrm{CT}$, aliada à ocorrência de $E$. coli, está associada, no nosso ponto de vista, à inexistência de saneamento básico na vila Olho d'Água e ao lançamento do esgoto doméstico, incluindo resíduos das fossas séticas construídas, nas margens dos rios Parafuso e Passarote. Além disso, é comum encontrarem-se criadouros de animais (bovinos, suínos e equinos) à beira destes rios.

De acordo com a resolução CONAMA n. ${ }^{\circ}$ 357/05, é permitida a concentração de até 1000 E. coli em $100 \mathrm{~mL}$ de água, para massas de água da classe 2. Os valores médios que encontrámos nos dois períodos de amostragem estão abaixo deste limite estabelecido pela legislação; todavia os resultados dos valores máximos e mínimos para os parâmetros de coliformes totais (48 NMP/100 mL e $24.196 \mathrm{NMP} / 100 \mathrm{~mL}$ ) e E. Coli (10 NMP/100 mL e $2755 \mathrm{NMP} / 100 \mathrm{~mL}$ ) levam a considerar a multifuncionalidade do rio Parafuso e do rio Passarote, pelo facto destes dois rios estarem inseridos no cotidiano dos moradores locais.

A pesquisa realizada em campo demonstra a multifuncionalidade do rio. É notória a importância e utilização dos rios para a comunidade, por ser considerado um espaço que abriga as diversas atividades humanas e, inclusive, um recurso para o consumo de água. O fornecimento da rede pública de água não abrange toda a comunidade local e existem problemas relacionados com a sua distribuição, que ocorre através de um sistema coletivo de poço artesiano.

Através da observação, in loco, a área de estudo encontra-se sobre forte pressão antrópica. A atividade pecuária, de bovinos, suínos e equinos, prolifera nas margens do rio, com a finalidade de facilitar o acesso destes animais aos referidos recursos. A urbanização desordenada, que tem ocorrido na área, determina a retirada da cobertura vegetal, tanto pelas atividades económicas, quanto pela construção de vias de acesso e infraestruturas necessárias ao processo de ocupação.

Considera-se que existe uma situação de risco sanitário nos referidos rios, não apresentando condições de potabilidade, com capacidade de transmissão de enfermidades de veiculação hídrica. Fica evidente que as águas dos rios Parafuso e Passarote estão em desacordo com as normas preconizadas pela Portaria n. ${ }^{\circ}$ 2914/2011, de 12 de dezembro, do Ministério da Saúde (BRASIL, 2011), que dispõe sobre os procedimentos de controlo e vigilância da qualidade da água para consumo humano e o seu padrão de potabilidade. A mesma determina que a água de consumo humano deve ter ausência total de E. coli, o principal indicador sanitário, situação contraditória na referida microbacia.

Relativamente ao saneamento básico, constata-se a inexistência de um aterro sanitário e a deficiente coleta diária de resíduos sólidos pela administração municipal. Muitos moradores da vila Olho d'Água depositam os seus resíduos sólidos urbanos nas margens dos rios, alterando a paisagem, servindo estes de abrigo para animais e insetos transmissores de doenças, que colocam em risco a saúde pública. A realidade ambiental observada na micobacia vai de encontro com a Política Nacional de Resíduos Sólidos ((Lei n. ${ }^{1}$ 12.305/2010, de 2 de agosto de 2010), que preconiza o correto gerenciamento e manejo destes resíduos, bem como o fechamento de todas as lixeiras a céu aberto em território nacional (BRASIL, 2010). A Lei Estadual 5887/1995, art. $700^{\circ}$, proíbe o lançamento de resíduos sólidos, coletados por sistemas de limpeza, públicos ou privados, nos cursos de água e no solo a céu aberto (PARÁ, 1995).

Entre as patologias declaradas pelos inquiridos, foi relatada a presença de doenças que podem ser veiculadas pela água, tais como diarreia (19\%), micoses $(11 \%)$ e verminoses (3\%). Também foi relatada a presença de enfermidades que apresentam o ciclo reprodutivo do agente patogénico relacionado com água, como a dengue (6\%), infeções transmitidas por via respiratória (53\%) 
e doenças do sistema muscular e osteoarticular de origem não traumática (3\%). Segundo os moradores locais, é no período de estiagem, quando o nível de água baixa e ocorre a diminuição da vazão dos rios, que as doenças veiculadas pela água aparecem com mais frequência.

\section{CONCLUSÃO E RECOMENDAÇÃO}

Os rios que constituem a microbacia hidrográfica do rio Parafuso apresentam multifuncionalidade económica, sociológica e estética e são importantes para os moradores locais, sobretudo para o lazer e fornecimento de água para execução das atividades domésticas cotidianas e produtivas. As atividades antropogénicas no assentamento Olho d'Água l e na vila Olho d'Água provocam alterações na qualidade das águas superficiais na microbacia de estudo.

As concentrações de Fe e de E. coli, em alguns pontos amostrais, ultrapassam os limites exigidos pela Resolução CONAMA n. ${ }^{\circ}$ 357/2005, para águas de classe 2, o que denota o comprometimento da qualidade da água para os diversos usos que a conunidade lhe dá. Estas constatações, aliadas à falta de saneamento na microbacia do rio Parafuso, demonstram a necessidade de políticas públicas que priorizem a saúde ambiental e a conservação da microbacia.

Entre as medidas capazes de minimizar os impactos sobre os cursos de água são recomendadas as seguintes ações: a) criação de um comité, com a participação de moradores locais, para gestão da bacia hidrográfica do rio Ubá e dos seus afluentes; b) implantação de programas interdisciplinares e participativos de monitoração periódica das massas de água na área de estudo; c) manutenção e restauração das áreas de preservação permanente, como sejam as matas ciliares; d) preservação e restauração das áreas que circundam as nascentes, conforme recomenda a Lei $12.651 \ldots$, de 25 de maio de 2012 (BRASIL, 2012); e) implementação de programas de educação ambiental que visem valorar os recursos naturais (faunísticos, florísticos, hídricos, solo) e estimulem o uso sustentável destes recursos naturais; e f) adoção de políticas públicas de saneamento, meio ambiente e saúde, que levem em conta o conhecimento científico e os saberes das populações locais.

\section{REFERÊNCIAS}

AGUIAR, Christiane Patrícia Oliveira de; PELEJA, José Reinaldo Pacheco; SOUSA, Keid Nolan Silva Qualidade da água em microbacias hidrográficas com agricultura nos municípios de Santarém e Belterra, Pará. Revista Árvore. [Em linha]. Vol. 38, n. ${ }^{\circ} 6$
(2014), p. 983-992. [Consult. 14 jul. 2016]. Disponível em WWW: URL: http://www.scielo.br/pdf/rarv/ v38n6/a03v38n6.pdf. ISNN 1806-9088.

ALVES, Igor Charles Castor; EL-ROBRINI, Maâmar; SANTOS, Maria de Lourdes Souza; MONTEIRO, Sury de Moura; BARBOSA, Leando Patrick Ferreira; GUIMARÃES, José Tasso Feliz - Qualidade das águas superficiais e avaliação do estado trófico do Rio Arari (Ilha de Marajó, norte do Brasil). Acta Amazónica. [Em linha] Vol. 42, n.॰ 1 (2012), p. 115-124. Disponível em WWW: URL: http://www.scielo.br/scielo.php?script=sci_arttext \&pid=S0044-59672012000100014. ISSN 0044-5967.

AMORIM, Sibele Queiroz; MATTA, Milton António da Silva; CAVALCANTE, Itabaraci Nazareno Nazareno; ASSIS, José Fernando Pina; MARTINS, Jorge Augusto Costa; DINIZ, Cesar Guerreiro, et al. - "Qualidade da água do manancial de abastecimento da cidade de Parauapebas - PA". Águas subterrâneas. 2010. [Em linha] [Consult. 18 ago. 2012]. Disponível em WWW: URL: https://aguassubterraneas.abas.org/ asubterraneas/article/view/23073. ISSN 2179-9784.

APHA, American Public Health Association. Standard Methods for the Examination of Water and Wastewater. 20 ${ }^{\text {th }}$ Ed.. APHA, AWWA, WEF. 2005.

BRASIL. Conselho Nacional do Meio Ambiente (CONAMA) - Resolução n. ${ }^{\circ}$ 357/2005, de 17 de março de 2005. [Em linha]. [Consult. 26 jul. 2006]. Disponível em WWW: URL: http://www.mma.gov.br.

BRASIL - Lei n. ${ }^{\circ}$ 12.305, de 2 de agosto de 2010. Diário Oficial da República Federativa do Brasil. [Em linha]. [Consult. 15 jun. 2012]. Disponível em WWW: URL: http://www.planalto.gov.br/ccivil_03/_ ato2007-2010/2010/lei/l12305.htm.

BRASIL. Ministério da Saúde - Portaria n. 2914, de 12 de dezembro de 2011. Diário Oficial da República Federativa do Brasil. [Em linha]. [Consult. 15 jun. 2012]. Diponível em WWW: URL: http://site. sabesp.com.br/site/uploads/file/asabesp_doctos/ PortariaMS291412122011.pdf.

BRASIL. Lei n.o 12.651, de 25 de maio de 2012. Diário Oficial da República Federativa do Brasil. [Em linha]. [Consult. 10 nov. 2013]. Diponível em WWW: URL:http://www.plan alto.gov.br/ccivil_03/_ ato2011-2014/2012/ lei/l12651.htm.

CETESB - Companhia Ambiental do Estado de São Paulo - Guia nacional de coleta e preservação de amostras. Brasília, DF: Agência Nacional de Águas, 2011.

ESTEVES, Francisco de Assis - Fundamentos de Limnologia. Rio de Janeiro: Interciência, 1998. ISBN 97-8857-1932-71-5. 
MOTA, Seutônio - Preservação e conservação de recursos hídricos. 2. a ed. Rio de Janeiro: ABES, 1995. ISBN 97-8857-0221-18-6.

MOTA, Seutônio - Introdução à Engenharia Ambiental. Rio de Janeiro: ABES, 1997. ISBN 8570221-39-8.

ORTEGA, Cristina; SOLO-GABRIELE, Helena M.; ABDELZAHER, Amir; WRIGHT, Mary; DENG, Yang; STARK, Lilian M. - Correlations between microbial indicators, pathogens, and environmental factors in a subtropical estuary. Marine Pollution Bulletin. [Em linha]. Vol. 58, n. 9 (2009), p. 1374-81. [Consult. 3 out. 2006]. Disponível em WWW: URL: https://www.ncbi.nlm.nih.gov/pmc/articles/ PMC2735792/. ISNN 0025-326X.

PAIVA, Rosildo Santos; ESKINAZI-LEÇA, Enide; PASSAVANTE, José Zanon de Oliveira; SILVA-CUNHA, Maria da Glória Gonçalves da; MELO, Nuno Filipe Alves Correia de - Considerações ecológicas sobre o fitoplâncton da baía do Guajará e foz do rio Guamá (Pará, Brasil). Boletim do Museu Paraense Emílio Goeldi. Ciências Naturais. [Em linha].Vol. 2, n. ${ }^{\circ} 1$ (2006), p. 133-146. [Consult. 14 jan. 2010]. Disponível em WWW: http://www.museu-goeldi.br/editora/ bn/artigos/cnv1n2_2006/fitoplancton(paiva).pdf.

PARÁ. Lei Estadual n. 5.887 , de 9 de Maio de 1995. Política Estadual do Meio Ambiente. Secretaria de Estado de Meio Ambiente. [Em linha]. [Consult. 25 mar. 2015]. Disponível em WWW: URL: http://www. semas.pa.gov.br/1995/05/09/9741/.

PEREIRA, Bruno Wendell de Freitas; MACIEL, Maria de Nazaré Martins; OLIVEIRA, Francisco de Assis; ALVES, Marcelo Augusto Moreno da Silva; RIBEIRO, Adriana Melo; FERREIRA, Bruno Monteiro; RIBEIRO, Ellen Gabriele Pinto - Uso da terra e degradação na qualidade da água na bacia hidrográfica do rio Peixe-Boi, PA, Brasil Revista Ambiente \& Água. [Em linha]. Vol. 11, n. 2 (2016), p. 472-85. [Consult. 10 ago. 2016]. Disponível em WWW: URL: http://www.scielo.br/pdf/ambiagua/v11n2/1980993X-ambiagua-11-02-00472.pdf. ISSN 1980-993X.

PINHEIRO, R. V. L. Estudo hidrodinâmico $e$ sedimentológico do estuário do Guajará-Belém (PA). 1987. Dissertação (Mestrado), Centro de Geociências. Universidade Federal do Pará, Belém.

REBOUÇAS, Aldo da C. "Água Doce no Mundo e no Brasil". In REBOUÇAS, Aldo da C., BRAGA, Benedito, TUNDISI, José G. (Orgs.) - Águas Doces no Brasil: Capital Ecológico, Uso e Conservação. 3..$^{\text {a ed. São }}$ Paulo: Escrituras, 2006. ISBN 85-8630-34-10.

RIBEIRO, Karla Tereza Silva Ribeira - A água e saúde humana em Belém. Belém: Cejup, 2004. ISBN 853380-46-1X.

ROSA, Leonilde dos Santos - Limites e possibilidades do uso sustentável dos produtos madeireiros $e$ não madeireiros na Amazônia brasileira: o caso dos pequenos agricultores da Vila Boa Esperança, em Mojú, no Estado do Pará. Tese (Doutorado em Desenvolvimento Sustentável do Trópico Úmido), Universidade Federal do Pará/Núcleo de Altos Estudos da Amazônia, Belém, 2002.

SANTOS, P. L., SILVA, J. M. L., SILVA, B. N. R., SANTOS, R. D., REGO, G. S. - Levantamento semidetalhado dos solos e avaliação da aptidão agrícola das terras para culturas de dendê e seringueira de uma área no município de Moju, Pará. Rio de Janeiro: EMBRAPA/ SNLCS. Projeto Moju, Pará. Relatório técnico, 1985.

SANTOS, Maria de Lourdes Souza; BORDALO, Adriana Oliveira; PEREIRA, José Almir Rodrigues; CHIRA, Pedro Andre; ALVES, Igor Charles Castor; SODRÉ, Silvana Socorro Veloso - Influência da expansão urbana na qualidade da água em reservatório da Região Amazônica (Belém, Pará). Boletim Técnico Científico do Cepnor/Tropical Journal of Fisheries and Aquatic Sciences. [Em linha]. Vol. 13, n.o 1 (2013), p. 15-22. [Consult. 10 ago. 2016] Disponível em WWW: URL: https://cepnor.ufra.edu. br/index.php?journal =tjfas\&page=article\&op= view\&path\%5B\%5D=1013\&path\%5B\%5D=516. ISNN: 1676-5664.

SHIBATA, Tomoyuki; SOLO-GABRIELE, Helens M.; FLEMING, Lora. E.; ELMIR, Samir - Monitoring marine recreational water quality using multiple microbial indicators in an urban tropical environment. Water Research. [Em linha]. Vol. 38, n. 1 (2004), p. 311931. [Consult. 10 ago. 2016]. Disponível em WWW: URL: https://www.ncbi.nlm.nih.gov/pmc/articles/ PMC2548301/. ISSN 0043-1354.

SILVA, Dirlene Ferreira da - Utilização de indicadores biológicos na avaliação da qualidade da água da Baía do Guajará e do Rio Guamá (Belém-Pará). Dissertação (Mestrado) - Universidade Federal do Pará, Centro de Ciências Agrárias, Núcleo de Estudos em Ciência Animal, 2006. [Em linha] [Consult. 21 mar. 2016]. Disponível em WWW: URL: http://repositorio.ufpa.br/jspui/bitstream/2011/4694/1/ Dissertacao_UtilizacaolndicadoresBiologicos.pdf.

SIOLI, H. - pH values to Amazonian waters. Bulletin of the Museum Paraense Emilio Goeldi. N.o 1 (1957), p. 1-35.

SIQUEIRA, Gilmar W.; APRILE, Fabio; MIGUÉIS, Antonio Miguel. Diagnóstico da qualidade da 
água do rio Parauapebas (Pará - Brasil). Acta Amazônica. [Em linha] Vol 42, n. 3 (2012), p. 413422. [Consult. 27 out. 2014]. Disponível em WWW: URL: http://www.scielo.br/scielo.php?script=sci_art text\&pid=S0044-59672012000300014.

SOUZA, Albanise Ferreira - Caracterização florística e estrutural da mata ciliar do rio parafuso, na bacia hidrográfica do rio Ubá, Moju-PA. Dissertação (Mestrado), Universidade Federal Rural da Amazônia, 2007.

SOUZA, Naziel Santos; SÁ-OLIVEIRA, Júlio César; SILVA, Erineide Silva - Avaliação da qualidade da água do alto rio pedreira, macapá-amapá. Biota Amazônia. [Em linha] Vol. 5 (2015), p. 10718. [Consult. 12 set. 2016]. Disponível em WWW: https://periodicos.unifap.br/index.php/biota/ article/view/1612/v5n2p107-118.pdf. ISSN 21795746.
VERDEJO, Miguel Expósito - Diagnóstico rural participativo: guia prático. Brasília DF: Ministério do Desenvolvimento Agrário, 2006. [Em linha] [Consult. 19 set. 2007]. Disponível em WWW: URL: http://www.mda.gov.br/sitemda/sites/sitemda/ files/user_arquivos_64/Guia_DRP_Parte_1.pdf. ISBN 978-85-60548-71.

ZUFFO, Cátia Eliza; NASCIMENTO, Gerson Flôres; ABREU, F. A. M.; CAVALCANTE, Itabaraci Nazareno Caracterização da Qualidade de Águas Superficiais em Rondônia. Anuário do Instituto de Geociências. [Em linha] Vol. 36.2, n. 1 (2013), p. 25-39. [Consult. 14 jul. 2016]. Disponível em WWW: URL: https://revistas. ufrj.br/index.php/aigeo/article/view/6960/5527. ISSN 0101-9759. 